\title{
On "Tables and Stools" in Court Musical Gathering
}

\author{
Miao Sun \\ School of Material Science and Engineering \\ Northeast Forestry University \\ Harbin, Heilongjiang, China 150040 \\ Qi Zhang \\ School of Material Science and Engineering \\ Northeast Forestry University \\ Harbin, Heilongjiang, China 150040
}

\author{
Yan $\mathrm{Gu}^{*}$ \\ School of Material Science and Engineering \\ Northeast Forestry University \\ Harbin, Heilongjiang, China 150040 \\ Xizhu Yin \\ School of Material Science and Engineering \\ Northeast Forestry University \\ Harbin, Heilongjiang, China 150040
}

\begin{abstract}
It was in Tang dynasty that art of furniture making experienced its integration and transition. After the most prosperous period of Tang, magnificent furniture that was completely distinctive from the previous styles was gradually popularized among the aristocrats, and categories of them were further added. The picture Court Musical Gathering which painted in late Tang Dynasty shows furniture of tables and stools of that era elaborately. Instead of presenting in antique styles, they were changed into unprecedented mellow and unique ones with resplendent decorations and bright colors. The texture and material of the furniture, that fully manifests the humanity feature of furniture in court during late Tang, can clearly be seen. And it reveals the free and broad mindsets of Tang people plus the craftsmanship and managerial development of many industries including woodworking, metal manufacturing, etc.
\end{abstract}

Keywords-Late Tang Dynasty; furniture; Court Musical Gathering

\section{BASIC SHAPES AND WORKMANSHIP OF FURNITURE IN COURT MUSICAL GATHERING}

Court Musical Gathering, an outstanding figure painting accomplished in late Tang [1], makes exquisite and realistic description of the scene of that time. It includes a total of 10 figures, either imperial concubines or maids, who sit around a big oblong table doing wine-drinking games for tea enjoying and playing instruments for musical appreciating. This painting not only reflects the prevalence of tea-drinking in late Tang Dynasty, but depicts the then furniture in a fine and realistic manner. Thus this drawing contains great researching values for those willing to study the art of furniture back then as well as other aspects "Fig. 1".

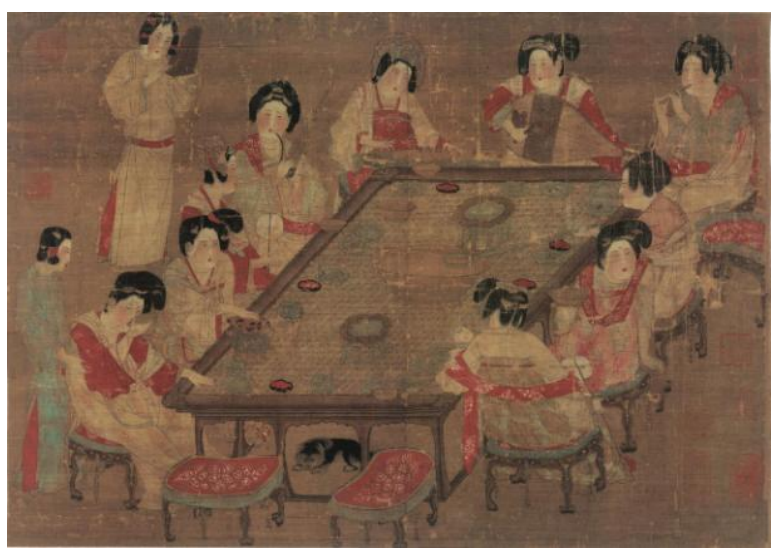

Fig. 1. Court Musical Gathering, Excerpted from Master Pieces of Chinese Figure Paintings

The grand table is in oblong shape and has bulges on each side of its edge. At the center of the table draws bamboo stria in dark green and each corner of it is wrapped with mental exterior. There are several layers from top to bottom with decreasing size of areas that make up the whole table. The four sides are decorated with pot-shaped doors, an irregular shape resembles the rough sketch of a Chinese tea pot that is frequently designed in Chinese constructions. According to proportional calculation, the numbers of doors on its length and width sides respectively are five and three. Wooden frames are added under every pot-shaped door before it touches the ground. It is built in a broad magnificent style with proper designing proportion. Compared with previous longer and narrower tables from both practical and aesthetic ways, this piece of furniture is improved and can be considered a new type since the Tang Dynasty. It shows the diversity of material people choose to use back then. Although this table cannot be discovered in any literature or in form of cultural relics, it is indispensable when imperial musical events are held, where small tables can neither hold 10 people nor show cheerful and lively atmosphere of the scene. So this piece can be inferred to be an indispensable furniture in court of late Tang.

There are 13 crescent-shaped stools, also named as wuzi and yaodeng in Chinese which means flats chairs with four 
legs and waistline shaped stools, which are functioned as stools nowadays. It is named possibly for its curved surfaces, which looks like the shape of a half-moon. Others argue that the name originates from the sunken design to support gravity center of human body when sitting on. Its structure and form is unique, only can be found in that period of time. The surface is in meniscus shape if observed from one side of it in the painting, and the central of which subsides and puts soft embroidered mat for comfortably sitting. Although without waist-like curved legs, the stool has fine gorgeous decorations on its surface. Two of the four legs of the stool are placed on edge of the meniscus with relatively longer distance, in order to accommodate human legs when sitting down and stretching. And the other two legs equally cut the curve of the meniscus into three parts with relatively shorter distance in between, in order to bear the concentrated pressure of hip sitting on them. The profile of feet and legs also appear in pot shape with complex outline and rhythmical concave and convex, while the legs are not manufactured with wooden frames. The foot with "hook-and-cloud resembled toes" appears in L shape with two heads facing up while bottom touches the ground. The legs are embellished with patterns. The designer adds metal rings to the middle of the legs on two sides of the stool and decorates them with tassels, which endows the hefty furniture with a bit of nifty sense.

The height and other sizes of these two pieces of furniture are similar to those of modern times. Specific restored shapes are as follows "Fig. 2":

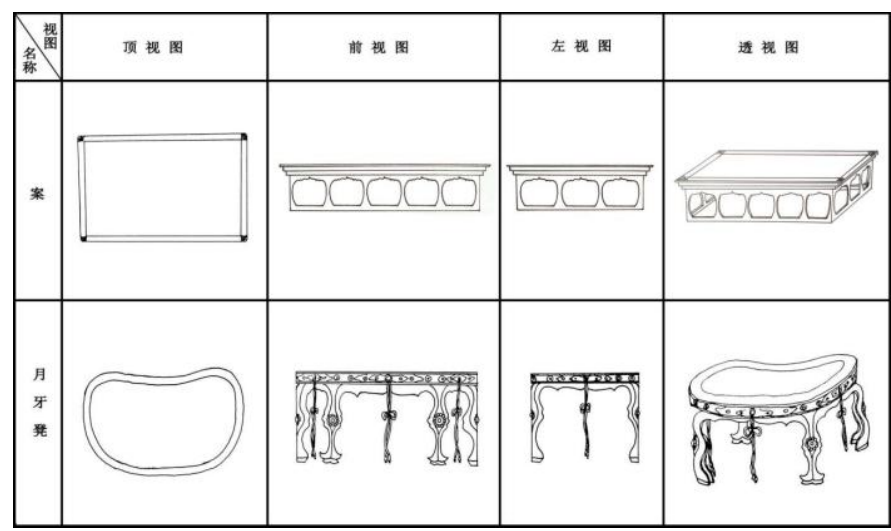

Fig. 2. All Sides View of Furniture in Court Musical Gathering, Source from Hand Painted

\section{DECORATING TECHNIQUE USED ON FURNITURE IN COURT Musical GATHERING}

Carving and inlaying are frequently applied to furniture in the picture. Pot-shaped sculpture is first used on the grand table in form of hollowed-out engraving to add the sense of stability to it. Four corners are bound with golden additions made by metal, as the herald of decorating corner of taller furniture with metal exterior. Patterns on the corner coverage are either simplified peony sketch influenced by pomegranate drawing that are popular during late Tang Dynasty, or treasured lotus peony-looking pictures in tiered cloud form[2].

Crescent stool has bright and gorgeous color with beautiful and complicated decorations and sculptured patterns. The contour of its legs and feet varies from each other and appears symmetrically from middle to both sides. Upper middle sides of each leg are engraved with simplified lotus figure at the turning points which combine leg with stool top. The patterns and figures are not only extremely resemble lotus sketches used to decorated Yungang grottoes, but also bear some similarities with mural figures in Indian Ajanta Caves built in 1 to 2 century B.C, but not as complex. It can be inferred that the lotus figure developed since Chinese Wei and Jin Dynasty has the same origination with the ancient Indian ones and has been inherited[3] and developed ever since. The stool is decorated with carved veins, and metal rings are added between two legs of it. The rest parts are sculptured with regular flower patterns and in the heart of which are inlaid with gems. Red flower adornments presumably left from color drawing are mingled with other decorations, thus craftsmanship and painting are interacted with each other in this piece of work as well as others at that period of time. It is worth noticing that the two stools nearest to viewers in the picture are not carved and decorated with any adornments or mental rings, whereas are suspended with silk decorations. Maybe metal rings are hidden under its surface. Red mats on top are embroidered with white flowers that are consistence with the color of silk flowers on the cloth of imperial personnel during late Tang Dynasty. The color looks matching and bright.

\section{SignifiCANCE OF THE FuRNITURE In COURT MuSICAL GATHERING}

Society and culture back then supported the development of the art, and by contrast, the art could also reflect all aspects of the society. The furniture in the Court Musical Gathering totally reflects the aesthetic fashion in the Late Tang Dynasty. Just like the body shape of the maids in royal court, it reveals a sense of beauty which is stocky and stable, just as the shining of jewelry. Its material, structure and decoration, with all blends into one harmonious whole, display the court life, technology transformation, and humanities changing. It not only changed the primitive and plain style of previous dynasties, but also brought a deep impact on the development of both Chinese and foreign furniture aftermath. It plays an irreplaceable role in the Chinese furniture history.

\section{A. A Reflection of the Social Situation in Late Tang Dynasty}

According to the Court Musical Gathering, it is obviously that the lifestyle had been changed, people used to enjoy pedal sitting. The style of furniture became rather gorgeous, and the types were also increasing. It not just showed the achievement of handicraft in late Tang Dynasty, the art of craft and decoration became exquisite, but displayed the pursuit of joys of living. After the An-shi Rebellion, the eunuch had seized the power, caused the chaos in officialdom, the government couldn't choose the suitable person for the job. Although had big hope for the "resurgence", the scholars understood well that they could do little to change the tide. Thus the scholars became interesting in joys of living, to get rid of their despair feeling. And it can be concluded from the picture. As to the theme and connotation of the decoration, the furniture displayed a rather different style from the former. The emperor was fatuous and powerless, the politics was not so brilliant and 
magnificent as it in Zhenguan and Kaiguan era. The social living tended to be tough, while the upper class became more and more extravagant. The noblemen used complicated living devices to show off their power and wealth. Furthermore, we can learn from the decorative pattern and find the impact of Buddhism on Tang Dynasty, not only for the average people, but also for the people in upper class. It had a great influence on the art and handicraft.

\section{B. A Revealing Achievement of the Handicraft in Tang Dynasty}

The material of the furniture in the picture also have some change, the material is not limited in lumber, other natural resource like bamboo, rattan are also used in furniture. In former dynasties, the products of bamboo usually were mat. It is first appeared in this picture that the mat was used as the cover of the desk. Though there is no clear evidence in history book on this skill, it can be deduced from the furniture in this picture, using mat in upper-style furniture became very popular in late Tang Dynasty. And this skill provides inspiration and lays foundation for the upper style furniture with bamboo, rattan and root in after age.

The modeling of the furniture in picture reflects the advancement of iron craft and carpenter tools. As to makingiron technology, frying iron technology became more advanced than it in former dynasties, which had been widely used in late Tang Dynasty. The booming of iron-making industry provided the convenience for producing carpenter tools. Of the tools, timber saw became popular in early Tang Dynasty[4], caused many change on the combination of carpenter tools, which made the time-wasting dissociation and chopping very convenient. Shaping lumber tools planter also can be traced back Tang Dynasty. The technology, with assistance of axe, can improve the smooth degree of the lumber. The tools of measurement and direction have some important advancement, the name of "splines" first came out in Tang Dynasty, quote from He Erya-- splines are the tools of craftsmen, and it also called Ruler of the Court Li of Tang Dynasty[5]. Coordinate implement of the new tools made building furniture easier, and the complex configuration can be achieved more convenient.

As to the decoration technology, the former dynasties before Tang usually used gold-plating technology. During Wei-Jin Era, some imported technology like hammer and count method, bead method just stayed in the bud. In Tang Dynasty, these methods became mature and developed exquisite technology. The concave and convex pattern in metal cornerite of the counter seems to be made by hammer and count method, its shape and structure clearly display the influence from the gold and silver ware from Sassanid Persia on China's craft and art. It also shows the social reality of the exquisite method of gold and silver ware in Tang Dynasty[6]. Putting metal material to the part which is easily abraded, not only strength the structure of furniture, but also enhance the sense of beauty. Boosting furniture to develop toward a practical and artistic way, it also lays foundation to the application of metal parts in furniture aftermath.

\section{An Expression of the Communication between Domestic and Foreign Culture}

The image of Kettle door originates from the middle gate of Buddhism buildings, which imported in China since the end of West Han Dynasty, going through six dynasties from Wei to Jin Era, it spread widely in late Tang Dynasty, which displayed the transition of religion and inherit in history. Except that, the Image of Buddha pattern is the best example to understand the combination between local and foreign culture. The pattern formed and flourished in Tang Dynasty, along with importing process of Buddhism. It was developed from lotus pattern. The lotus pattern before Han Dynasty, was actually the Chinese water lily. People used to mix lotus and water lily. Chinese people believe lotus is a holy flower since ancient time, the flower was believed not just belonging to the earth, but belonging to heaven. As early as Han Dynasty, the lotus pattern had already a clear script record, and the material object had been discovered. The cryptic relation between lotus and gods in heaven was adored by rulers. All these factors give lotus a unique implication. In India, lotus enjoys same rank as the God of Sun or Creator, which can be seen as the holy item which give birth to everything. After the rise of Buddhism, lotus is also seen as the incarnation of Buddha himself. The flower, differs from the Chinese version, is the candock. Although there has some difference between the two cultures, but the love of lotus boosts the development of the pattern in China. Other patterns like holy elder or god didn't spread as widely as lotus. At early stage, the Chinese version lotus had relatively less petals, mostly has 4 to 8 , mixed the foreign culture with local Fengshui theory, expressed the sense of "Four Directions and Eight Position", the petals became more aftermath, from the pattern in the legs of waist stool, the petals had grown to 12 .

\section{An Expression the Aesthetic Appreciation of Tang People}

Except for craft technology and religion communication, the furniture in picture also display the ideal aesthetic creation for Tang people, which has more imagination and delight of freedom than former dynasties. The furniture, without the bound of feudal ethical code originated from Shang and Zhou Era, had come into daily life. Its modeling is elegant, full and round, became very different from the aesthetic standard from Wei and Jin Era, which is "Fresh Frame and Light Image". On the decoration of furniture, the pursuit of beauty become more human kindness, reduced the image of magical creature, and be full of natural interesting. Take silk tassel as an example, it bring a vivid sense on solid furniture and made it full of life.

\section{CONCLUSION}

Court Musical Gathering describes a scene of life, it more like an epitome of court life in late Tang Dynasty. The furniture on picture displayed the transition of shape, and also displayed the social fashion transformed from conservative to free and easy, as well as peaceful and exquisite. Its style is different from the rough style in the early Tang Dynasty, and laying foundation of the development of furniture in Five Dynasties and Ten Kingdoms Era. On texture, with combined bamboo mat and lumber frame, it obviously displays the historical inherit, and the worship and love of natural item. On 
decoration, from the simply purified complex pattern, it shows the wit and sense of beauty for the craftsmen on that time. The primitive and peaceful counter cooperates to the dynamic stool organically. On the ratio of furniture, both the height of counter and stool is a bit lower than it of modern furniture, the ratio of height of counter and stools is 9:5, which is very similar with the modern one. There is a Kettle door structure beneath the counter, which made people cannot put legs under the counter, thus the person who sit on the stool couldn't stay in a serous position. From this we can deduce that the counter cannot be used in former situation, and more likely to be used in an entertainment area. The stool on that period was used by women, and it can be proved by Picture of Practicing and Working and the Portrait of a Lady with a Fan. In other pictures, we still cannot found it was used by men, thus we can deduced that the stool was a kind of typical furniture for women during the transition period in the history of furniture. On the structure, according to the skill of craftsmen, it should mainly include straight tenon, dowel and 45 angel Corner tenon, probably use the metal parts to strengthen the structure, the making of case was the original stage of the technology which assemble and trough at the same time. We can also deduce from the lacquer painting on the case of the counter, the stools were very likely made of soft lumber such as pine or Ginkgo. All in all, the politics in late Tang Dynasty is dark, while the art of furniture became a beam in the darkness. It developed as before, and absorbed the foreign cultural element, which lay foundation to the furniture aftermath. It shows the sprite of Tang people, which is tolerant and open-minded, as well as keeping pace with the times.

\section{REFERENCES}

[1] Liu Rendao. Complete Works of Famous Paintings of Ancient Characters in China [J], Chinese Drama Publishing House, 2001.

[2] Long Caifeng, Research on Application of Typical Plant Patterns of Tang Dynasty in Home Design, Central South University of Forestry and Technology, 2012.

[3] Xu Cui, Research on Art Symbol of Baoxiang Patterns in Tang Dynasty, Hunan University of Technology, 2009.

[4] Li Zhen, Carpentry Tools of Chinese Traditional Architecture, Tongji University Press, 2004.

[5] Li Zhen, Carpentry Tools of Chinese Traditional Architecture, Tongji University Press, 2004.

[6] Shang Gang, New Edition of History of Arts and Craft in China, Higher Education Press, 2007.

[7] Zhang Huaicheng. Chinese Academic History, Volume of Sui and Tang Dynasties, People's Publishing House, 2003.

[8] Li Xifan, Qin Xu, Chinese Academic History, Volume of Sui and Tang Dynasties, Part I, Beijing Normal University Press, 2006.

[9] Li Xifan, Qin Xu, Chinese Academic History, Volume of Sui and Tang Dynasties, Part II, Beijing Normal University Press, 2006.

[10] Xu Han, Chinese Art Encyclopedia, Volume Ten, People's Publishing House, 2005.

[11] Lin Pengcheng. Famous Paintings of Characters in Tang Dynasty and Five Dynasties and Song Dynasty, Xiling Seal Engraver's Society Publishing House, 2006.

[12] He Hongkui, Furniture Culture and Art, China Building Industry Press, 2013.

[13] [America] Stanley Weinstein, translated by Zhan Yu, Buddhism in the Tang Dynasty, Shanghai Chinese Classics Publishing House, 1987.
[14] Li Zhen, Transition of Carpentry Tools and Development of Furniture after Sui and Tang Dynasties, the 3rd edition of Historical Buildings.

[15] Hua Jueming, Analects of History of Metallurgy in China, Cultural Relics Publishing House, 1986.

[16] Lu Yucheng, Artistic Features of Arts and Crafts in Tang Dynasty, Hundred Schools in Arts, the 6th edition, 2005.

[17] Han Jizhong, Preliminary Study of Furniture in Tang Dynasty, 1985. 